03.1;05.1;06.3;09.3;13.1;14.4;15.2

\title{
Разрушение пленки золота при моделировании процесса лазерной биопечати
}

\author{
(С В.С. Жигарьков, Н.В. Минаев, В.И. Юсупов \\ Институт фоотонных технологий ФНИЦ „Кристаллография и фотоника“ РАН, Москва, Троицк, Россия \\ E-mail: vzhigarkov@gmail.com
}

Поступило в Редакцию 7 октября 2020 г.

В окончательной редакции 17 марта 2021 г.

Принято к публикации 17 марта 2021 г.

\begin{abstract}
Лазерная печать гелевыми микрокаплями является перспективным методом для биотехнологии и медицины. В процессе печати наносекундный лазерный импульс поглощается в тонком слое металлической пленки донорной подложки, на поверхность которого нанесен слой геля (например, раствор гиалуроновой кислоты, агара и т.д.), что приводит к нагреванию и частичному разрушению пленки и переносу микрокапли геля на акцепторную подложку. Исследована динамика разрушения пленки золота толщиной $50 \mathrm{~nm}$. Показано, что при превышении порога адгезии пленки первоначально происходит отслоение золотой пленки от стеклянной подложки, а дальнейшее увеличение плотности энергии лазерного излучения приводит к разрушению пленки с образованием отверстия. Полученные результаты представляют интерес для совершенствования технологии лазерной биопечати.
\end{abstract}

Ключевые слова: лазерный импульс, микрокапля геля, поглощающая пленка, отслоение пленки, адгезия.

DOI: 10.21883/PJTF.2021.12.51059.18575

Технология лазерной печати гелевыми микрокаплями находит широкое применение в задачах биомедицинского направления $[1,2]$. Для осуществления печати на донорную стеклянную подложку с тонкой поглощающей металлической пленкой наносится слой геля с клетками или микроорганизмами. Поглощение импульсного лазерного излучения приводит к локальному нагреву пленки и переносу микрокапли геля на акцепторную подложку [3]. В процессе печати металлическая пленка может частично разрушаться, что приводит к нежелательному переносу с гелевыми микрокаплями наночастиц материала пленки. Поэтому для совершенствования технологии лазерной биопечати необходимо подобрать оптимальные режимы лазерного воздействия. Целью настоящей работы является изучение особенностей разрушения пленки золота толщиной $50 \mathrm{~nm}$ на донорной подложке при лазерной биопечати в диапазоне лазерных флюенсов вблизи порога разрушения пленки.

В качестве источника импульсного излучения в эксперименте использовался волоконный лазер YLPM-1-4x200-20-20 (ООО НТО „ИРЭ-Полюс“, Россия) с $\lambda=1064 \mathrm{~nm}$, длительностью импульсов $8 \mathrm{~ns}$ и энергией в импульсе $E=2-900 \mu \mathrm{J}$ [3]. Излучение c помощью объектива F-theta фокусировалось на поверхность металлической пленки толщиной $\sim 50 \mathrm{~nm}$ донорной подложки в пятно диаметром $\sim 100 \mu \mathrm{m}$. На пленку наносился слой геля - $2 \%$ водный раствор гиалуроновой кислоты толщиной $\sim 200 \mu \mathrm{m}$.

В центр области импульсного лазерного воздействия (схема на рис. $1, a$ ) под углом $40^{\circ}$ к нормали к поверхности донорной подложки осуществлялась фокусировка пробного пучка гелий-неонового лазера с $\lambda=633 \mathrm{~nm}$ (размер пятна $\sim 30 \mu \mathrm{m}$ ). Интенсивность отраженного луча $\mathrm{He}-\mathrm{Ne}$-лазера регистрировалась с помощью фотоприемника с полосой пропускания до $1.7 \mathrm{GHz}$. Степень разрушения пленки золота при лазерной печати определялась по снимкам сканирующего электронного микроскопа (СЭМ) PHENOM ProX (Phenom World, Нидерланды) с использованием обычного и топографического режимов. Коэффициенты поглощения и отражения многослойной системы $\mathrm{SiO}_{2} / \mathrm{Au} / \mathrm{H}_{2} \mathrm{O}$ (рис. 1,a) определялись с помощью программы Filmetrics (США). Так, для лазерного излучения коэффициент поглощения в пленке составил $A(1064 \mathrm{~nm}) \sim 0.03$, а коэффициент отражения $R(633 \mathrm{~nm}) \sim 0.78$.

На рис. 1, $b$ показана динамика интенсивности отраженного от пленки золота пучка гелий-неонового лазера. Видно, что импульсное воздействие с $\lambda=1064 \mathrm{~nm}$ приводит к изменениям коэффициента отражения пленки $\mathrm{Au}$. Такие изменения при малых значениях энергии импульса $E$ носят кратковременный характер. При $E=50 \mu \mathrm{J}\left(140 \mathrm{~mJ} / \mathrm{cm}^{2}\right)$ интенсивность отраженного пучка уменьшилась на $25 \%$, а через $0.5 \mu$ s уже полностью восстановилась до прежнего уровня. Для $E=55 \mu \mathrm{J}$ $\left(150 \mathrm{~mJ} / \mathrm{cm}^{2}\right)$ уменьшение было более значительным и длилось $\sim 5 \mu \mathrm{s}$. Дальнейшее увеличение энергии $E$ необратимо уменьшает отражательную способность пробного пучка от поверхности пленки.

На рис. 2 приведены СЭМ-изображения участков пленки $\mathrm{Au}$ после лазерных импульсных воздействий $(\lambda=1064 \mathrm{~nm})$. Как видно из рис. $2, a$, при $E=55 \mu \mathrm{J}$ разрушения поверхности пленки не происходит, а при бо́льших значениях $E$ наблюдается появление разрывов пленки и образование в ней отверстий. С помощью топографического режима СЭМ (рис. 2, $b$ ) удалось установить, что помимо нарушения целостности металли- 

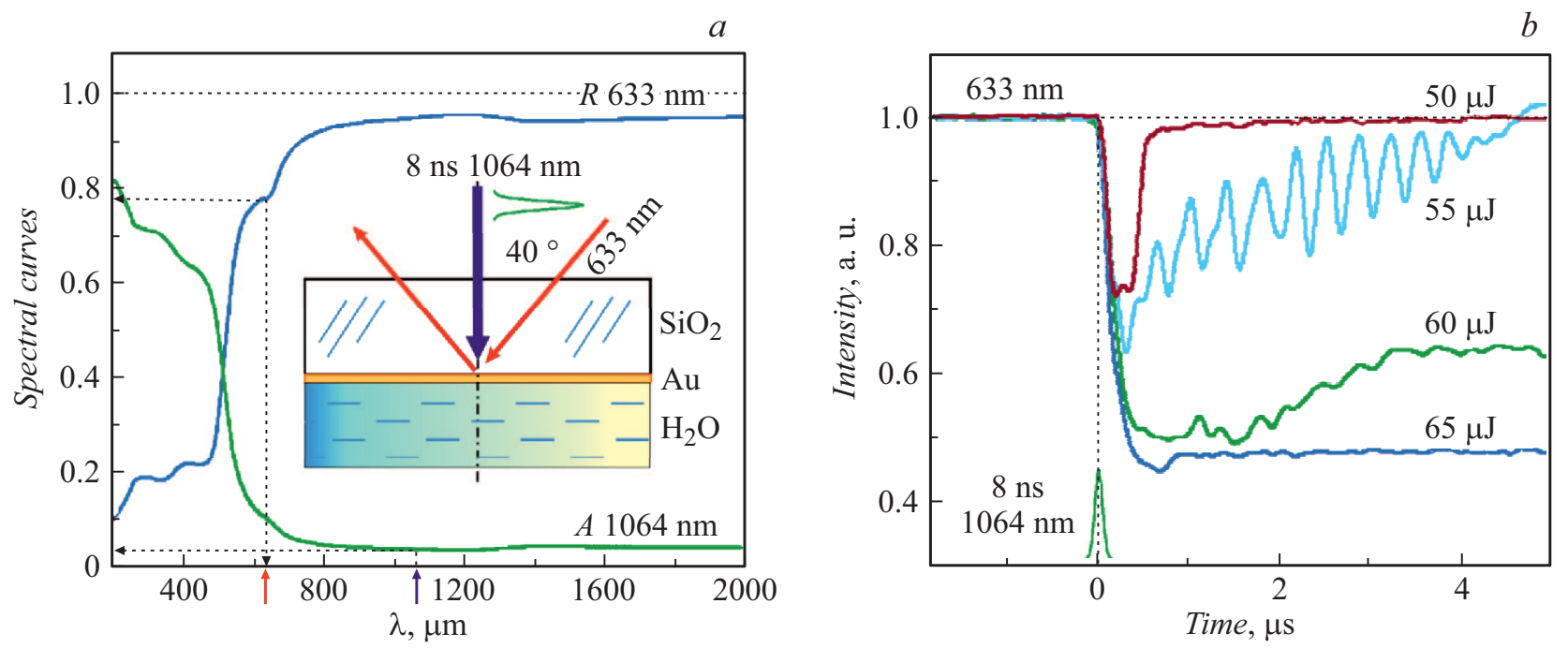

Рис. 1. $a-$ спектры поглощения $(A)$ лазерного излучения $1064 \mathrm{~nm}$ и отражения $(R)$ лазерного излучения $\lambda=633 \mathrm{~nm}$ в многослойной системе $\mathrm{SiO}_{2} / \mathrm{Au} / \mathrm{H}_{2} \mathrm{O}$ (по схеме, представленной на вставке); $b$ - динамика интенсивности отраженного от пленки золота пробного пучка $\lambda=633 \mathrm{~nm}$ при лазерном воздействии с $\lambda=1064 \mathrm{~nm}$ и различных энергиях в импульсе.

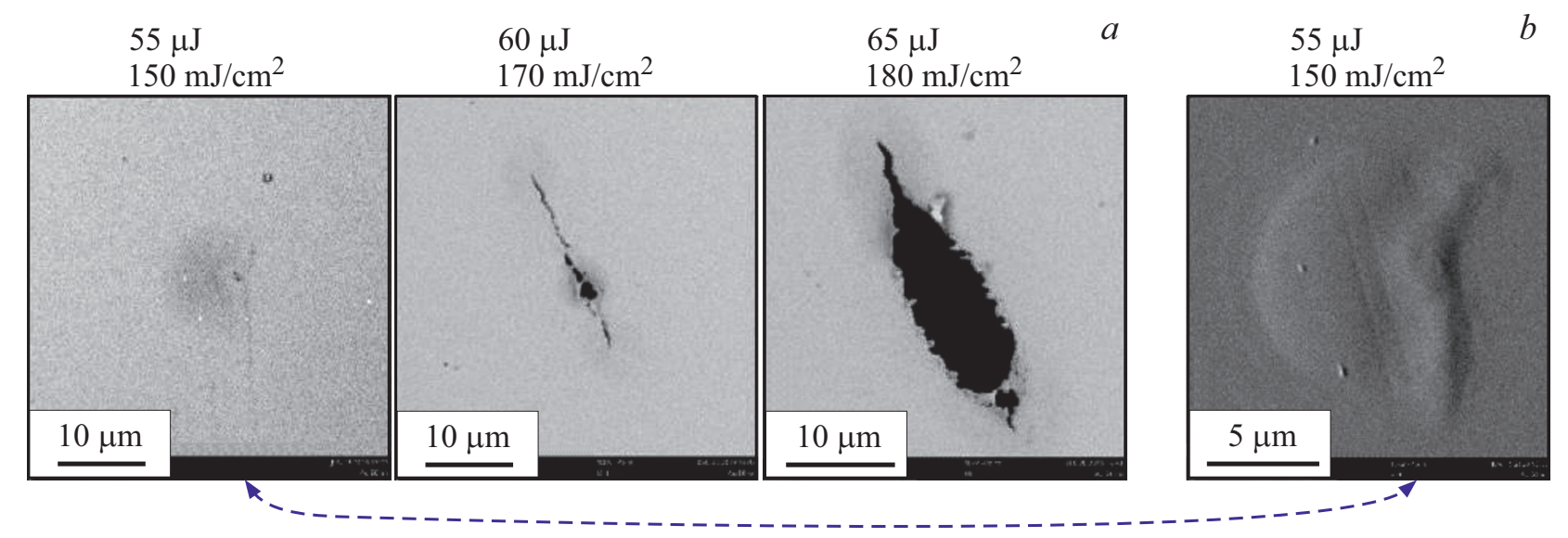

Рис. 2. СЭМ-изображения поверхностей золотой пленки в области импульсного лазерного воздействия при различных энергиях в импульсе. $a-$ обычный режим, $b-$ топографический режим.

ческой пленки может происходить ее отслоение от стеклянной пластинки. Так, при $E=55 \mu \mathrm{J}$ отчетливо наблюдается вспучивание пленки на участке размером $\sim 15 \mu \mathrm{m}$.

Известно, что отражательная способность золота при $\lambda=633 \mathrm{~nm}$ монотонно уменьшается с увеличением температуры и при температуре плавления $\left(T_{m}=1064^{\circ} \mathrm{C}\right)$ составляет $\sim 94 \%$ от исходного уровня [4]. Поскольку при минимальном значении энергии $E=50-55 \mu \mathrm{J}$ разрушения пленки не происходит (рис. 2,a), температура ее нагрева не достигает $T_{m}$. Однако при этом интенсивность пробного пучка падает на $25-30 \%$ (рис. $1, b$ ). Этот эффект может быть объяснен тем, что происходит отрыв и вспучивание пленки (рис. 2,b), что также приводит к уменьшению интенсивности отраженного луча $\mathrm{He}-\mathrm{Ne}$-лазера.
Отслоением пленки можно объяснить и возникновение цуга колебаний сигнала отраженного пучка гелий-неонового лазера при $E=55 \mu \mathrm{J}$ (рис. $1, b$ ). Мы полагаем, что эти колебания возникают из-за интерференции лучей пробного пучка в условиях, когда часть пленки оторвана от подложки. Легко подсчитать, что для появления биений с частотой $\sim 3 \mathrm{MHz}$ (рис. $1, b)$ скорость перемещения оторвавшейся части пленки должна составлять $\sim 1.5 \mathrm{~m} / \mathrm{s}$.

Представленные СЭМ-изображения (рис. 2,a) показывают, что наблюдаемые при $E \geqslant 60 \mu \mathrm{J}\left(170 \mathrm{~mJ} / \mathrm{cm}^{2}\right)$ необратимые уменьшения отражательной способности пленки $\mathrm{Au}$ (рис. $1, b$ ) связаны с появлением в ней разрывов и образованием отверстий.

Механизм отрыва пленки при лазерном импульсном нагреве хорошо известен (см., например, [5]). Причиной отрыва является тепловое расширение золота при лазер- 
ном нагреве. Такое расширение в условиях жесткой границы со стороны стекла приводит к появлению у пленки результирующего импульса, направленного в сторону воды (см. схему на рис. $1, a$ ). Пленка держится на стекле за счет адгезии, величина которой обычно значительно меньше предела прочности материала пленки. В нашем случае порог отрыва пленки от стекла $(E \sim 55 \mu \mathrm{J})$ оказался несколько ниже ее порога плавления $(E \sim 60 \mu \mathrm{J})$.

Таким образом, в работе исследована динамика изменения морфологии и разрушения пленки золота толщиной $50 \mathrm{~nm}$ при поглощении $8 \mathrm{~ns}$ лазерного импульса с $\lambda=1064 \mathrm{~nm}$ в режиме, близком к лазерной биопечати. Показано, что вблизи порога плавления золотой пленки происходит ее отслоение от стеклянной пластинки с образованием вспучивания. Увеличение энергии лазерного излучения приводит к образованию разрывов и отверстий в пленке с возможным переносом части материала в виде микро/наночастиц Аu вместе с гелевой микрокаплей $[1,3]$. Полученные результаты представляют интерес для совершенствования технологии лазерной биопечати.

\section{Финансирование работы}

Работа выполнена при поддержке Министерства науки и высшего образования в рамках выполнения работ по государственному заданию ФНИЦ „Кристаллография и фотоника“ РАН в части калибровки лазерной системы и гранта РНФ 20-14-00286 в части совершенствования технологии лазерной инженерии микробных систем.

\section{Конфликт интересов}

Авторы заявляют, что у них нет конфликта интересов.

\section{Список литературы}

[1] V.I. Yusupov, M.V. Gorlenko, V.S. Cheptsov, N.V. Minaev, E.S. Churbanova, V.S. Zhigarkov, E.A. Chutko, S.A. Evlashin, B.N. Chichkov, V.N. Bagratashvili, Laser Phys. Lett., 15 (6), 065604 (2018). https://doi.org/10.1088/1612-202X/aab5ef

[2] T.V. Kochetkova, K.S. Zayulina, V.S. Zhigarkov, N.V. Minaev, B.N. Chichkov, A.A. Novikov, S.V. Toshchakov, A.G. Elcheninov, I.V. Kublanov, Int. J. Syst. Evol. Microbiol., 70 (2), 1192 (2020). https://doi.org/10.1099/ijsem.0.003902

[3] В.И. Юсупов, В.С. Жигарьков, Е.С. Чурбанова, Е.А. Чутко, С.А. Евлашин, М.В. Горленко, В.С. Чепцов, Н.В. Минаев, В.Н. Баграташвили, Квантовая электроника, 47 (12), 1158 (2017). http://dx.doi.org/10.1070/QEL16512

[4] J. Boneberg, J. Bischof, P. Leiderer, Opt. Commun., 174 (1-4), 145 (2000). https://doi.org/10.1016/S0030-4018(99)00660-4

[5] А.В. Феденев, Е.И. Липатов, В.Ф. Тарасенко, В.М. Орловский, М.А. Шулепов, Н.Н. Коваль, И.М. Гончаренко, Квантовая электроника, 34 (4), 375 (2004). http://dx.doi.org/10.1070/QE2004v034n04ABEH002683 